\title{
Review
}

Fetal Diagnosis

and Therapy

\section{Neurodevelopment after Fetal Growth Restriction}

\author{
Ahmet A. Baschat \\ Center for Advanced Fetal Care, Department of Obstetrics and Gynecology and Reproductive Sciences, University of \\ Maryland School of Medicine, Baltimore, Md., USA
}

\section{Key Words}

Umbilical artery blood flow resistance $\cdot$ Fetal growth

restriction $\cdot$ Neurodevelopment $\cdot$ Head growth

\begin{abstract}
Fetal growth restriction (FGR) can emerge as a complication of placental dysfunction and increases the risk for neurodevelopmental delay. Marked elevations of umbilical artery (UA) Doppler resistance that set the stage for cardiovascular and biophysical deterioration with subsequent preterm birth characterize early-onset FGR. Minimal, or absent UA Doppler abnormalities and isolated cerebral Doppler changes with subtle deterioration and a high risk for unanticipated term stillbirth are characteristic for late-onset FGR. Nutritional deficiency manifested in lagging head growth is the most powerful predictor of developmental delay in all forms of FGR. Extremes of blood flow resistance and cardiovascular deterioration, prematurity and intracranial hemorrhage increase the risks for psychomotor delay and cerebral palsy. In late-onset FGR, regional cerebral vascular redistribution correlates with abnormal behavioral domains. Irrespective of the phenotype of FGR, prenatal tests that provide precise and independent stratification of risks for adverse neurodevelopment have yet to be determined.
\end{abstract}

(c) 2013 S. Karger AG, Basel

\section{Introduction}

Fetal growth restriction (FGR) secondary to placental dysfunction is associated with a range of adverse longterm outcomes. Among these, neurodevelopment has received considerable attention because it can have a profound impact on the quality of life and potential of the individual $[1,2]$. Because the developing brain exhibits plasticity as well as a limited potential for regeneration following injury, it is important to understand the antecedents of abnormal neurodevelopment in order to determine the potential for prevention [3]. One of the challenges in understanding these antecedents is the variation of the risk profile that is determined by the clinical phenotype of FGR. The aim of this overview is to provide an estimate of the neurodevelopmental impact of various aspects of the disease.

\section{Phenotype and Risk Profile of Early- and Late-Onset Fetal Growth Delay}

Early- and late-onset FGR represents two distinct clinical phenotypes of placental dysfunction [4]. Early-onset FGR is associated with reduced placental perfusion due to a decrease in villous cross-sectional vascular area, which

\section{KARGER}

E-Mail karger@karger.com

www.karger.com/fdt
2013 S. Karger AG, Basel

$1015-3837 / 13 / 0362-0136 \$ 38.00 / 0$
Ahmet A. Baschat, MD, Center for Advanced Fetal Care

Department of Obstetrics and Gynecology and Reproductive Sciences University of Maryland School of Medicine

22 South Greene Street, Room 6NE12, Baltimore, MD 21201 (USA)

E-Mail aabaschat@hotmail.com 
leads to elevated umbilical artery (UA) blood flow resistance once villous damage exceeds 30\% [4]. Typically, FGR is established by the second trimester, and the diagnostic hallmark is the combination of fetal measurements below the 10th percentile in association with abnormal UA Doppler [5]. Late-onset FGR is established in the third trimester. It is more common than early-onset disease, and is associated with a range of placental abnormalities including villous immaturity that interfere with gas and nutrient exchange but have less pronounced effects on villous vascular resistance [6]. Therefore, UA Doppler may be normal, but the fetus may react with decreased middle cerebral artery (MCA) impedance in response to hypoxemia [7]. Because of the variations in underlying placental disease, the diagnostic hallmark of lateonset FGR is a small fetal size $<10$ th percentile associated with any of the following: (1) elevated UA Doppler index, (2) decreased cerebroplacental Doppler ratio (UA/MCA index), (3) decrease in the MCA Doppler index even if the $\mathrm{UA}$ is normal [4].

Following the time of diagnosis, early- and late-onset FGR differ significantly in clinical progression. In earlyonset disease, elevated UA Doppler resistance is followed by MCA brain sparing, escalating blood flow resistance in the UA with progressive reverse shunting in the aortic isthmus followed by deterioration of venous Doppler parameters and finally the biophysical profile score. Progression to the point of delivery, typically taking 4-6 weeks, is determined by the timing of UA end-diastolic velocity reversal. In contrast, in late-onset FGR progression may take up to 9 weeks and is subtle; UA Doppler may be normal, a decrease in the CPR may occur or isolated MCA brain sparing may be observed [8]. Biophysical abnormalities may not extend beyond loss of heart rate reactivity or decrease in the amniotic fluid index [4]. Due to these differences in clinical behavior nutritional deprivation, fetal deterioration and delivery considerations also differ in their timing in relationship to fetal neurodevelopmental milestones.

\section{FGR and Delay in Fetal Neurodevelopment}

Fetal developmental milestones correlate with the transition of neurogenesis to accelerating synaptogenesis reflecting the increasing sophistication of central regulation of physiological and behavioral variables [9-11]. In the first trimester, individual activities such as tone and breathing occur randomly. By 20 weeks, diurnal variation of fetal movement and heart rate patterns, with increased activity in the second half of the day, emerges [12]. Coupling of physiological inputs (e.g. linking of fetal breathing frequency to maternal glucose levels) and rest-activity cycles become established from 26 to 28 weeks $[13,14]$. Fetal heart rate reactivity in response to movement, fully established by 32 weeks' gestation, allows correlation of heart rate patterns to behavioral states. Fetal behavioral states $1 \mathrm{~F}-4 \mathrm{~F}$, which correspond to their neonatal counterparts, are established between 32 and 36 weeks' gestation $[15,16]$. At this time, there is also integration of behavioral and cardiovascular control that allows modulation of individual vascular beds during different behavioral states [17-21]. The factors that regulate this neuronal maturation include sufficient nutrient delivery as well as immune and endocrine placental-fetal interactions [3].

Early-onset FGR is associated with delay of fetal neurodevelopmental milestones [22-24]. Behavioral state establishment and heart rate reactivity may be delayed by up to 4 weeks. In contrast, late FGR occurs after establishment of behavioral states, and therefore is more likely to result in abnormal movement quality and state transitions [25-30]. Despite this delay in intrauterine behavioral development, the FGR fetus retains the sequential loss of dynamic variables in response to worsening metabolic status [14].

Although the relationship between placental dysfunction and fetal neurodevelopmental delay is recognized, there is limited information about the long-term developmental impact of this prenatal delay [1]. A decrease in the amount of movements is more likely a response to deepening hypoxemia and is less predictive of 2-year motor delay $[31,32]$. In contrast, abnormal fetal movement quality, particularly if persistent beyond delivery, has a stronger relationship with motor delay at age 2 [33-37].

\section{Parameters of Fetal Growth and Neurodevelopment}

In the fetus, nutrient delivery and cardiovascular dynamics are linked, and nutrient streams are partitioned at three important sites: the ductus venosus (DV), foramen ovale and aortic isthmus [38]. Decrease in transplacental nutrient delivery triggers DV redistribution of venous return at the expense of the liver. When placental blood flow resistance is elevated or when MCA brain sparing is triggered, there is redistribution of cardiac output toward the myocardium and brain [38]. However, the relative increase in blood flow resistance in the descending aorta also promotes retrograde shunting of nutrient-poor 
blood through the aortic isthmus toward the brain [38]. The timing and magnitude of these vascular modifications in nutrient partitioning are also related to the growth pattern. Typically, liver growth and abdominal circumference (AC) lag first, while head growth is spared producing the clinical picture of asymmetric growth restriction. With persistent severe placental dysfunction, eventually head growth may no longer be maintained and the fetus becomes symmetrically small (abdomen and head are equally affected) $[1,4,38-40]$.

Widely utilized prenatal measures of fetal size include the estimated fetal weight, the head circumference (HC), $\mathrm{AC}$ and $\mathrm{HC} / \mathrm{AC}$ ratio expressed as percentiles. Small fetal head size is one of the most powerful prenatal predictors of adverse neurodevelopment, independent of gestational age or the degree of fetal compromise of Doppler or biophysical parameters. In early-onset FGR, a disproportional reduction in head growth and overall reduction of fetal size predict cerebral palsy, psychomotor and cognitive development $[41,42]$. In late-onset FGR, slowing head growth is associated with a decrease in perceptional performance, motor ability, cognition, concentration ability and defects in short-term memory, with subsequently poorer school achievement [43]. The relationship between head growth and neurodevelopment appears to be a continuum as each standard deviation in size decrease increases the rate of suboptimal outcome by $10 \%$ in one study [44].

The powerful impact of decreased head size on neurodevelopment suggests that cerebral nutritional deprivation during the evolution of placental dysfunction is a central mechanism mediating developmental impacts [1].

\section{Impact of Cardiovascular Compromise on Neurodevelopment}

Most Doppler studies do not control for the clinical phenotype of FGR or the degree of cardiovascular information that is required to accurately reflect the degree of compromise $[1,2]$. The majority of studies evaluate single, mostly arterial vascular beds, which is a confounder in early-onset FGR where widespread cardiovascular responses are characteristic. This is less of an issue for lateonset FGR where Doppler abnormalities typically do not extend beyond the cerebral circulation.

In early-onset FGR, loss of UA and descending aortic end-diastolic velocity are associated with abnormal acid base balance, decrease in the CPR or MCA PI correlated with deepening hypoxemia, and abnormal venous Doppler parameters provide the closest stratification for acidemia and stillbirth risk [4]. Absent or reversed UA enddiastolic velocity (UA AREDV) has an independent impact on neurodevelopment from the late second trimester onward. This is reflected in lower motor developmental index at age 2 and lower cognitive performance thereafter $[45,46]$. In childhood, UA AREDV survivors have more than twice the rate of major neurologic sequelae and a $10 \%$ higher rate of minor neurologic sequelae, while the intelligence quotient is similar [47]. At age 6 years, fine motor and gross motor scores are over $20 \%$ lower than in AGA controls, and Kaufman ABC scores are lower for all domains [48, 49]. In particular reversed end-diastolic velocity is an independent risk factor for adverse motor and cognitive development all the way to adolescence [50].

In early-onset FGR requiring delivery prior to 30 weeks, neonates with prenatal evidence of cardiac compromise are likely to have the worst motor development [51-55]. In fetuses with milder placental disease delivered between 30 and 31 weeks delivered prior to DV deterioration, MCA brain sparing is associated with lower scores in areas of habituation, social-interactive, motor performance and attention [56]. However, neither venous, cerebral or central Doppler studies, nor the biophysical profile score add risk stratification that is independent of the UA Doppler status, gestational age at delivery and the degree of growth restriction and confounders such as steroid use and neonatal complications, especially intracranial hemorrhage [57-60].

Late-onset FGR babies are at increased risk for lower cognitive developmental scores irrespective of prenatal Doppler status. When the UA Doppler is abnormal, the rate of suboptimal neurodevelopment at age 2 may be as high as 15\% [61]. The impact on behavioral domains such as attention, habituation, motor, social-interactive and state regulation seems to predominate in small for gestational age neonates [62] and translates to significantly lower scores in the problem solving and social domains compared to AGA controls [63]. These domains are related to frontal lobe function, and several observations support the concept that this area of the brain is especially vulnerable to fetal nutrient deficiency in the third trimester [64]. When cerebral artery Doppler findings are considered, it becomes apparent that regional specialization of the fetal brain and regional changes in cerebral blood flow resistance interact to produce specific developmental abnormalities. MCA brain sparing is associated with lower ASQ scores in communication, problem solving and personal-social areas [65]. A larger study that 
evaluated impedance changes in anterior and middle cerebral vascular territories showed that the former were related to emotional-reactive, attention and somatic scores, while the latter related only to somatic complaint scores [66]. Power Doppler studies utilizing more sensitive techniques provide evidence of regional shifts in cerebral perfusion that occur even earlier before measurable differences in individual cerebral vascular beds can be measured with conventional Doppler $[67,68]$.

\section{Fetal Deterioration before Delivery}

The basic concept that fetal deterioration prior to delivery has a long-term impact is based on cordocentesis data indicating a closer relationship between neurodevelopment with acidemia rather than hypoxemia [69]. It is difficult to translate these findings in clinical studies that evaluate birth $\mathrm{pH}$ since the latter may be related to prenatal deterioration as well as intrapartum events. Several studies have considered the birth $\mathrm{pH}$ in addition to other parameters defining the severity of FGR. Only one study indicated that a $\mathrm{pH}<7.00$ may be a cofactor for a low Bayley or Griffiths score $<85$ [55].

An abnormal biophysical profile score can be considered as strong evidence for a prelabor $\mathrm{pH}<7.20$ and has been shown to be associated with an increased risk for cerebral palsy in unselected populations $[14,70]$. However, early-onset FGR does not have an independent impact on 2-year neurodevelopment [53]. In less severe forms of early-onset FGR, incremental vascular deterioration beyond the UA Doppler affects several behavioral domains [56]. Similarly, in late-onset FGR, patients that are delivered for maternal rather than fetal indications tend to have better neurodevelopmental outcomes [61, 71]. One can hypothesize that in these studies improved neurodevelopment occurred because delivery occurred before fetal deterioration. To this date, it remains to be determined which prenatal testing parameters stratify the type of fetal deterioration that is most predictive of neurodevelopment.

Several studies indicate that current surveillance parameters do not achieve this. Recent observational studies indicate that neither UA status nor cerebral Doppler studies stratified the risk for cognitive development in term FGA pregnancies [72, 73]. In the DIGITAT trial, randomization of delivery timing with safety criteria to intervene for fetal indications did not produce any significant differences in early infant development either [74]. It therefore appears that in early-onset IUGR there are a multitude of additional factors dictated by disease severity that have a far greater impact on neurodevelopment than fetal deterioration prior to delivery. In term FGA, however, deterioration seems to have a contributing effect, and it remains to be determined which prenatal measures provide the best definition of the associated neurodevelopmental impact.

\section{Impact of Delivery Timing}

The timing of delivery determines the gestational age when transition to extrauterine life occurs. The majority of studies in FGR pregnancies are observational, where gestational age at delivery is determined by several factors including the speed and degree of fetal deterioration, physician preference and local practices. In the randomized GRIT and DIGITAT trials, delayed delivery was essentially timed by the physician perception that ongoing expectant management is no longer safe $[75,76]$. Accordingly, evaluating the precise relationship between fetal surveillance parameters that defined the delivery indication and neurodevelopment is only possible through secondary analyses. In contrast, the TRUFFLE study specified delivery criteria for the randomization arms, and therefore will allow examination of the developmental impact of these decision indicators [77]. Despite these limitations, important information on the impact of delivery timing on neurodevelopment has emerged.

In early-onset FGR, gestational age at delivery shows a consistent independent relationship with parameters of motor development with a maximum impact for infants delivered before 28 weeks [ $53,54,78-80]$. This impact is independent of other variables of fetal disease such as the severity of growth delay and the degree of cardiovascular and biophysical deterioration. In the GRIT study, $98 \%$ of patients completed 2-year follow-up. The rate of cerebral palsy was greater for patients randomized to immediate delivery prior to 31 weeks' gestation, and prematurityrelated complications were important contributors to this risk [81]. Based on several studies, the rate of cerebral palsy for early-onset FGR ranges between 8 and 12\% for women delivered before 32 weeks [53, 55, 81, 82]. The predominance of motor impact and the contributory role of neonatal complications suggest that intraventricular hemorrhage is an important mediating factor for poor neurodevelopment [57-60]. A smaller proportion of GRIT participants completed standardized assessment of cognition, language, behavior and motor ability at 6-13 years. There were no differences in the rates of severe dis- 
ability and individual domain scores between the two delivery arms, and results were comparable to other preterm cohorts without FGR [83].

The findings of the DIGITAT trial in term small for gestational age children confirm observational data indicating that gestational age difference at delivery does not contribute to 2-year neurodevelopment for patients delivered beyond 38 weeks gestation $[72,74]$. For patients delivered before that, several observational studies indicate that gestational age is related to motor, socialinteractive, habituation and cognitive subscales $[62,71$, 84].

These studies suggest that in early-onset FGR, gestational age itself and the prematurity-associated liabilities determine childhood motor development. In late-onset FGR, gestational age becomes a smaller contributor, and further studies are necessary to determine which fetal variables at the time of delivery are the main determinants of neurodevelopment [85].

\section{Conclusions}

There is great heterogeneity in the studies evaluating neurodevelopment in patients with FGR. This is due to the fact that our understanding of the clinical phenotype of early and late FGR is actively evolving. As a consequence, the classification of fetal disease has to be inferred from studies' findings rather than a uniform application of prospective classification. Despite these differences, the following principal concepts are emerging.

In-early onset FGR, the nutritional and vascular restriction in placental function limits the neurodevelopment potential. Prenatally, this is evident through the late achievement of fetal milestones. The magnitude of impairment relates to the degree of restriction of head and body growth. Placental Doppler is the most powerful predictor of the clinical deterioration and the circumstances surrounding delivery. With gestational age as the major determinant, fetal status at delivery and prematurity-related complications interact as determinants of neurodevelopment. It remains to be determined if interventions other than modulating disease course have any hope at improving neurodevelopment.

In late FGR, the significant nutritional impact occurs when fetal behavioral states have emerged. Nutritional deprivation impacts on behavioral domains rather than motor functions. As the impact of prematurity is no longer an issue, identifying prenatal markers for adverse neurodevelopment holds greater promise than in earlyonset FGR. To this date, these markers have not been sufficiently delineated to guide clinical management.

\section{References}

1 Baschat AA: Neurodevelopment following fetal growth restriction and its relationship with antepartum parameters of placental dysfunction. Ultrasound Obstet Gynecol 2011;37: 501-514.

2 Arcangeli T, Thilagnathan B, Hooper R, Khan KS, Bhide A: Neurodevelopmental delay in small babies at term: a systematic review. Ultrasound Obstet Gynecol 2012;40:267-275.

- 3 Gleeson JG, Polleux F: Neurodevelopment and disease. Curr Opin Neurobiol 2012;22: 735-736.

4 Baschat AA: Fetal growth restriction - from observation to intervention. J Perinat Med 2010;38:239-246.

$\checkmark 5$ Baschat AA, Weiner CP: Umbilical artery Doppler screening for detection of the small fetus in need of antepartum surveillance. Am J Obstet Gynecol 2000;182:154-158.

-6 Arabin B, Jimenez E, Vogel M, Weitzel HK: Relationship of utero- and fetoplacental blood flow velocity wave forms with pathomorphological placental findings. Fetal Diagn Ther 1992;7:173-179.
7 Bahado-Singh RO, Kovanci E, Jeffres A, Oz U, Deren O, Copel J, Mari G: The Doppler cerebroplacental ratio and perinatal outcome in intrauterine growth restriction. Am J Obstet Gynecol 1999;180:750-756.

8 Hernandez-Andrade E, Stampalija T, Figueras F: Cerebral blood flow studies in the diagnosis and management of intrauterine growth restriction. Curr Opin Obstet Gynecol 2013; 25:138-144.

9 Nijhuis JG: Behavioural states: concomitants, clinical implications and the assessment of the condition of the nervous system. Eur J Obstet Gynecol Reprod Biol 1986;21:301-308.

10 Pillai M, James D: Development of human fetal behavior: a review. Fetal Diagn Ther 1990; 5:15-32.

11 Bourgeois JP: Synaptogenesis, heterochrony and epigenesis in the mammalian neocortex. Acta Paediatr Suppl 1997;422:27-33.

12 de Vries JI, Visser GH, Mulder EJ, Prechtl HF: Diurnal and other variations in fetal movement and heart rate patterns at 20-22 weeks. Early Hum Dev 1987;15:333-348.
13 Arduini D, Rizzo G, Giorlandino C, Valensise H, Dell'Acqua S, Romanini C: The development of fetal behavioural states: a longitudinal study. Prenat Diagn 1986;6:117-124.

14 Manning FA: Fetal biophysical profile. Obstet Gynecol Clin North Am 1999;26:557-577.

15 Nijhuis JG, Prechtl HF, Martin CB Jr, Bots RS: Are there behavioural states in the human fetus? Early Hum Dev 1982;6:177-195.

-16 Arduini D, Rizzo G, Giorlandino C, Vizzone A, Nava S, Dell'Acqua S, Valensise H, Romanini C: The fetal behavioural states: an ultrasonic study. Prenat Diagn 1985;5:269-276.

17 van Eyck J, Wladimiroff JW, Noordam MJ, Tonge HM, Prechtl HF: The blood flow velocity waveform in the fetal descending aorta: its relationship to fetal behavioural states in normal pregnancy at 37-38 weeks. Early Hum Dev 1985;12:137-143.

18 van Eyck J, Wladimiroff JW, van den Wijngaard JA, Noordam MJ, Prechtl HF: The blood flow velocity waveform in the fetal internal carotid and umbilical artery; its relation to fetal behavioural states in normal pregnancy at 37-38 weeks. Br J Obstet Gynaecol 1987; 94:736-741. 
19 van Eyck J, Stewart PA, Wladimiroff JW: Human fetal foramen ovale flow velocity waveforms relative to behavioral states in normal term pregnancy. Am J Obstet Gynecol 1990; 163:1239-1242.

20 van der Mooren K, van Eyck J, Wladimiroff JW: Human fetal ductal flow velocity waveforms relative to behavioral states in normal term pregnancy. Am J Obstet Gynecol 1989; 160:371-374.

-21 Rizzo G, Arduini D, Valensise H, Romanini C: Effects of behavioural states on cardiac output in the healthy human fetus at 36-38 weeks of gestation. Early Hum Dev 1990;23:109115.

-22 Arduini D, Rizzo G, Caforio L, Boccolini MR, Romanini C, Mancuso S: Behavioural state transitions in healthy and growth retarded fetuses. Early Hum Dev 1989;19:155-165.

-23 Arduini D, Rizzo G, Romanini C, Mancuso S: Computerized analysis of behavioural states in asymmetrical growth retarded fetuses. J Perinat Med 1988;16:357-363.

-24 Nijhuis IJ, ten Hof J, Nijhuis JG, Mulder EJ, Narayan H, Taylor DJ, Visser GH: Temporal organisation of fetal behaviour from 24-weeks gestation onwards in normal and complicated pregnancies. Dev Psychobiol 1999;34:257268.

25 Nijhuis IJ, ten Hof J, Mulder EJ, Nijhuis JG, Narayan H, Taylor DJ, Visser GH: Fetal heart rate in relation to its variation in normal and growth retarded fetuses. Eur J Obstet Gynecol Reprod Biol 2000;89:27-33.

26 Henson G, Dawes GS, Redman CW: Characterization of the reduced heart rate variation in growth-retarded fetuses. Br J Obstet Gynaecol 1984;91:751-755.

-27 van Vliet MA, Martin CB Jr, Nijhuis JG, Prechtl HF: The relationship between fetal activity and behavioral states and fetal breathing movements in normal and growth-retarded fetuses. Am J Obstet Gynecol 1985; 153:582588.

28 Dornan JC, Ritchie JW, Ruff S: The rate and regularity of breathing movements in the normal and growth-retarded fetus. Br J Obstet Gynaecol 1984;91:31-36.

-29 van Vliet MA, Martin CB Jr, Nijhuis JG, Prechtl HF: Behavioural states in growth retarded human fetuses. Early Hum Dev 1985; 12:183-197.

30 Vindla S, James D, Sahota D: Computerised analysis of unstimulated and stimulated behaviour in fetuses with intrauterine growth restriction. Eur J Obstet Gynecol Reprod Biol 1999;83:37-45.

-31 Pillai M, James D: Continuation of normal neurobehavioural development in fetuses with absent umbilical arterial end- diastolic velocities. Br J Obstet Gynaecol 1991;98:277281.

- 32 Groome LJ, Singh KP, Bentz LS, Holland SB, Atterbury JL, Swiber MJ, Trimm RF 3rd: Temporal stability in the distribution of behavioral states for individual human fetuses. Early Hum Dev 1997;48:187-197.
3 Bos AF, van Loon AJ, Martijn A, van Asperen RM, Okken A, Prechtl HF: Spontaneous motility in preterm, small-for-gestational age infants. I. Quantitative aspects. Early Hum Dev 1997;50:115-129.

34 Einspieler C, Prechtl HF, Ferrari F, Cioni G, Bos AF: The qualitative assessment of general movements in preterm, term and young infants - review of the methodology. Early Hum Dev 1997;50:47-60.

35 Bekedam DJ, Visser GH, de Vries JJ, Prechtl HF: Motor behaviour in the growth retarded fetus. Early Hum Dev 1985;12:155-165.

- 36 Prechtl HF, Einspieler C, Cioni G, Bos AF, Ferrari F, Sontheimer D: An early marker for neurological deficits after perinatal brain lesions. Lancet 1997;349:1361-1363.

37 Bos AF, van Loon AJ, Hadders-Algra M, Martijn A, Okken A, Prechtl HF: Spontaneous motility in preterm, small-for-gestational age infants. II. Qualitative aspects. Early Hum Dev 1997;50:131-147.

-38 Baschat AA: The fetal circulation and essential organs-a new twist to an old tale. Ultrasound Obstet Gynecol 2006;27:349-354.

39 Divon MY, Chamberlain PF, Sipos L, Manning FA, Platt LD: Identification of the small for gestational age fetus with the use of gestational age-independent indices of fetal growth. Am J Obstet Gynecol 1986;155:11971201.

40 Harrington K, Thompson MO, Carpenter RG, Nguyen M, Campbell S: Doppler fetal circulation in pregnancies complicated by preeclampsia or delivery of a small for gestational age baby. 2. Longitudinal analysis. $\mathrm{Br} \mathrm{J} \mathrm{Ob}-$ stet Gynaecol 1999;106:453-466.

-41 Harvey D, Prince J, Bunton J, Parkinson C, Campbell S: Abilities of children who were small-for-gestational-age babies. Pediatrics 1982;69:296-300.

42 Harel S, Tomer A, Barak Y, Binderman I, Yavin E: The cephalization index: a screening device for brain maturity and vulnerability in normal and intrauterine growth retarded newborns. Brain Dev 1985;7:580-584.

43 Parkinson CE, Scrivener R, Graves L, Bunton J, Harvey D: Behavioural differences of school-age children who were small-for-dates babies. Dev Med Child Neurol 1986;28:498505.

44 van Batenburg-Eddes T, de Groot L, Steegers EA, Hofman A, Jaddoe VW, Verhulst FC, Tiemeier H: Fetal programming of infant neuromotor development: the generation $\mathrm{R}$ study. Pediatr Res 2010;67:128-129.

45 Vossbeck S, de Camargo OK, Grab D, Bode $H$, Pohlandt F: Neonatal and neurodevelopmental outcome in infants born before 30 weeks of gestation with absent or reversed end-diastolic flow velocities in the umbilical artery. Eur J Pediatr 2001;160:128-134.

6 Morsing E, Asard M, Ley D, Stjernqvist K, Marsál K: Cognitive function after intrauterine growth restriction and very preterm birth. Pediatrics 2011;127:e874-e882.
47 Valcamonico A, Accorsi P, Battaglia S, Soregaroli M, Beretta D, Frusca T: Absent or reverse end-diastolic flow in the umbilical artery: intellectual development at school age. Eur J Obstet Gynecol Reprod Biol 2004;114: 23-28.

48 Wienerroither $\mathrm{H}$, Steiner H, Tomaselli J, Lobendanz M, Thun-Hohenstein L: Intrauterine blood flow and long-term intellectual, neurologic, and social development. Obstet Gynecol 2001;97:449-453.

49 Kutschera J, Tomaselli J, Urlesberger B, Maurer U, Häusler M, Gradnitzer E, Burmucic K, Müller W: Absent or reversed end-diastolic blood flow in the umbilical artery and abnormal Doppler cerebroplacental ratio-cognitive, neurological and somatic development at 3 to 6 years. Early Hum Dev 2002;69:47-56.

-50 Schreuder AM, McDonnell M, Gaffney G, Johnson A, Hope PL: Outcome at school age following antenatal detection of absent or reversed end diastolic flow velocity in the umbilical artery. Arch Dis Child Fetal Neonatal Ed 2002;86:F108-F114.

-51 Kaukola T, Rasanen J, Herva R, Patel DD, Hallman M: Suboptimal neurodevelopment in very preterm infants is related to fetal cardiovascular compromise in placental insufficiency. Am J Obstet Gynecol 2005;193:414-420.

52 Leppänen M, Ekholm E, Palo P, Maunu J, Munck P, Parkkola R, Matomäki J, Lapinleimu $\mathrm{H}$, Haataja L, Lehtonen L, Rautava P, the PIPARI Study group: Abnormal antenatal Doppler velocimetry and cognitive outcome in very-low birth weight infants at 2 years of age. Ultrasound Obstet Gynecol 2010;36: 178-185.

53 Baschat AA, Viscardi RM, Hussey-Gardner B, Hashmi N, Harman C: Infant neurodevelopment following fetal growth restriction: relationship with antepartum surveillance parameters. Ultrasound Obstet Gynecol 2009; 33:44-50.

54 Gerber S, Hohlfeld P, Viquerat F, Tolsa JF, Vial Y: Intrauterine growth restriction and absent or reverse end-diastolic blood flow in umbilical artery (Doppler class II or III): a retrospective study of short- and long-term fetal morbidity and mortality. Eur J Obstet Gynecol Reprod Biol 2006;126:20-26.

-55 Torrance HL, Bloemen MC, Mulder EJ, Nikkels PG, Derks JB, de Vries LS, Visser GH: Predictors of outcome at 2 years of age after early intrauterine growth restriction. Ultrasound Obstet Gynecol 2010;36:171-177.

56 Figueras F, Cruz-Martinez R, Sanz-Cortes M, Arranz A, Illa M, Botet F, Costas-Moragas C, Gratacos E: Neurobehavioral outcomes in preterm, growth-restricted infants with and without prenatal advanced signs of brainsparing. Ultrasound Obstet Gynecol 2011;38: 288-294.

57 Scherjon S, Oosting H, Ongerboer de Visser B, de Wilde T, Zondervan HA, Kok JA: Fetal brain sparing is associated with shortening of visual evoked potential latencies. Am J Obstet Gynecol 1996;175:1569-1575. 
58 Scherjon SA, Oosting H, Smolders-DeHaas H, Zondervan HA, Kok JH: Neurodevelopmental outcome at three years of age after fetal 'brainsparing'. Early Hum Dev 1998;52:67-79.

59 Scherjon S, Briet J, Oosting H, Kok J: The discrepancy between maturation of visualevoked potentials and cognitive outcome at five years in very preterm infants with and without hemodynamic signs of fetal brainsparing. Pediatrics 2000;105:385-391.

-60 van den Broek AJ, Kok JH, Houtzager BA, Scherjon SA: Behavioural problems at the age of eleven years in preterm-born children with or without fetal brain sparing: a prospective cohort study. Early Hum Dev 2010;86:379-384.

61 McCowan LM, Pryor J, Harding JE: Perinatal predictors of neurodevelopmental outcome in small-for-gestational-age children at 18 months of age. Am J Obstet Gynecol 2002; 186:1069-1075.

-62 Figueras F, Oros D, Cruz-Martinez R, Padilla N, Hernandez-Andrade E, Botet F, CostasMoragas C, Gratacos E: Neurobehavior in term, small-for-gestational age infants with normal placental function. Pediatrics 2009; 124:e934-e941.

-63 Figueras F, Eixarch E, Meler E, Iraola A, Figueras J, Puerto B, Gratacos E: Small-forgestational-age fetuses with normal umbilical artery Doppler have suboptimal perinatal and neurodevelopmental outcome. Eur J Obstet Gynecol Reprod Biol 2008;136:34-38.

-64 Sanz-Cortés M, Figueras F, Bargalló N, Padilla N, Amat-Roldan I, Gratacós E: Abnormal brain microstructure and metabolism in small-for-gestational-age term fetuses with normal umbilical artery Doppler. Ultrasound Obstet Gynecol 2010;36:159-165.

-65 Eixarch E, Meler E, Iraola A, Illa M, Crispi F, Hernandez-Andrade E, Gratacos E, Figueras F: Neurodevelopmental outcome in 2-yearold infants who were small-for-gestational age term fetuses with cerebral blood flow redistribution. Ultrasound Obstet Gynecol 2008;32:894-899.

- 66 Roza SJ, Steegers EA, Verburg BO, Jaddoe VW, Moll HA, Hofman A, Verhulst FC, Tiemeier $\mathrm{H}$ : What is spared by fetal brain-sparing? Fetal circulatory redistribution and behavioral problems in the general population. Am J Epidemiol 2008;168:1145-1152.

-67 Cruz-Martinez R, Figueras F, Hernandez-Andrade E, Puerto B, Gratacós E: Longitudinal brain perfusion changes in near-term smallfor-gestational-age fetuses as measured by spectral Doppler indices or by fractional moving blood volume. Am J Obstet Gynecol 2010; 203:42.e1-e6.
68 Mula R, Savchev S, Parra M, Arranz A, Botet F, Costas-Moragas C, Gratacos E, Figueras F: Increased fetal brain perfusion and neonatal neurobehavioral performance in normally grown fetuses. Fetal Diagn Ther 2013;33:182188.

69 Soothill PW, Ajayi RA, Campbell S, Ross EM, Nicolaides KH: Fetal oxygenation at cordocentesis, maternal smoking and childhood neuro-development. Eur J Obstet Gynecol Reprod Biol 1995;59:21-24.

70 Manning FA, Bondaji N, Harman CR, Casiro O, Menticoglou S, Morrison I, Berck DJ: Fetal assessment based on fetal biophysical profile scoring. VIII. The incidence of cerebral palsy in tested and untested perinates. Am J Obstet Gynecol 1998;178:696-706.

71 Gortner L, van Husen M, Thyen U, Gembruch U, Friedrich HJ, Landmann E: Outcome in preterm small for gestational age infants compared to appropriate for gestational age preterms at the age of 2 years: a prospective study. Eur J Obstet Gynecol Reprod Biol 2003;110:S93-S97.

72 Llurba E, Baschat AA, Turan OM, Harding J, McCowan LM: Childhood cognitive development after fetal growth restriction. Ultrasound Obstet Gynecol 2013;41:383-389.

73 Savchev S, Sanz-Cortes M, Cruz-Martinez R, Arranz A, Botet F, Gratacos E, Figueras F: Neurodevelopmental outcome of full-term, small-for-gestational-age infants with normal placental function. Ultrasound Obstet Gynecol 2013, E-pub ahead of print.

74 van Wyk L, Boers KE, van der Post JA, van Pampus MG, van Wassenaer AG, van Baar AL, Spaanderdam ME, Becker JH, Kwee A, Duvekot JJ, Bremer HA, Delemarre FM, Bloemenkamp KW, de Groot CJ, Willekes C, Roumen FJ, van Lith JM, Mol BW, le Cessie S, Scherjon SA, DIGITAT Study Group: Effects on (neuro)developmental and behavioral outcome at 2 years of age of induced labor compared with expectant management in intrauterine growth-restricted infants: longterm outcomes of the DIGITAT trial. Am J Obstet Gynecol 2012;206:406.e1-e7.

75 Boers KE, Bijlenga D, Mol BW, LeCessie S, Birnie E, van Pampus MG, Stigter RH, Bloemenkamp KW, van Meir CA, van der Post JA, Bekedam DJ, Ribbert LS, Drogtrop AP, van der Salm PC, Huisjes AJ, Willekes C, Roumen FJ, Scheepers HC, de Boer K, Duvekot JJ, Thornton JG, Scherjon SA: Disproportionate Intrauterine Growth Intervention Trial At Term: DIGITAT. BMC Pregnancy Childbirth 2007;7:12.
6 Baschat AA, Odibo AO: Timing of delivery in fetal growth restriction and childhood development: some uncertainties remain. Am J Obstet Gynecol 2011;204:2-3.

77 Lees C, Baumgartner H: The TRUFFLE study - a collaborative publicly funded project from concept to reality: how to negotiate an ethical, administrative and funding obstacle course in the European Union. Ultrasound Obstet Gynecol 2005;25:105-107.

78 Sung IK, Vohr B, Oh W: Growth and neurodevelopmental outcome of very low birth weight infants with intrauterine growth retardation: comparison with control subjects matched by birth weight and gestational age. J Pediatr 1993;123:618-624.

79 Padilla N, Perapoch J, Carrascosa A, AcostaRojas R, Botet F, Gratacós E: Twelve-month neurodevelopmental outcome in preterm infants with and without intrauterine growth restriction. Acta Paediatr 2010;99:1498-1503.

80 Shand AW, Hornbuckle J, Nathan E, Dickinson JE, French NP: Small for gestational age preterm infants and relationship of abnormal umbilical artery Doppler blood flow to perinatal mortality and neurodevelopmental outcomes. Aust N Z J Obstet Gynaecol 2009;49: 52-58.

-81 Thornton JG, Hornbuckle J, Vail A, Spiegelhalter DJ, Levene M, GRIT study group: Infant wellbeing at 2 years of age in the Growth Restriction Intervention Trial (GRIT): multicentred randomised controlled trial. Lancet 2004;364:513-520.

82 Brodszki J, Morsing E, Malcus P, Thuring A, Ley D, Marsàl K: Early intervention in management of very preterm growth-restricted fetuses: 2-year outcome of infants delivered on fetal indication before 30 gestational weeks. Ultrasound Obstet Gynecol 2009;34: 288-296.

83 Walker DM, Marlow N, Upstone L, Gross H, Hornbuckle J, Vail A, Wolke D, Thornton JG: The Growth Restriction Intervention Trial: long-term outcomes in a randomized trial of timing of delivery in fetal growth restriction. Am J Obstet Gynecol 2010;204:34.e1-e9.

-84 Ley D, Tideman E, Laurin J, Bjerre I, Marsal $\mathrm{K}$ : Abnormal fetal aortic velocity waveform and intellectual function at 7 years of age. Ultrasound Obstet Gynecol 1996;8:160-165.

-85 Egaña-Ugrinovic G, Sanz-Cortes M, Figueras F, Bargalló N, Gratacós E: Differences in cortical development assessed by fetal MRI in late-onset intrauterine growth restriction. Am J Obstet Gynecol 2013, E-pub ahead of print. 